Brit. Heart F., 1968, 30, 84.

\title{
Factors Affecting Cardioversion of Atrial Arrhythmias with Special Reference to Quinidine*
}

\author{
JOHN I. HALL AND DAVID R. WOOD \\ From the Departments of Cardiology, Royal Infirmary and Western General Hospital, Edinburgh
}

Synchronized direct current shock (Lown, Amarasingham, and Neuman, 1962) has rapidly become established as an effective and safe method of treating cardiac arrhythmias, but controversy remains about the use of antiarrhythmic drugs in maintaining sinus rhythm following the procedure. Although quinidine is potentially dangerous (Thomson, 1956; Oram and Davies, 1964 ; Davies, Leak, and Oram, 1965), many authors state that it should be used prophylactically (Lown et al., 1963; Hurst et al., 1964 ; Korsgren et al., 1965 ; Morris, Peter, and McIntosh, 1966). However, Halmos (1966) and Szekely, Batson, and Stark (1966) have suggested that quinidine does not prolong the duration of sinus rhythm.

In this paper we describe our experience in using direct current shock to treat 149 patients with atrial arrhythmias. The effect of prophylactic quinidine on the maintenance of sinus rhythm in a group of patients with rheumatic heart disease is compared with another group on no quinidine. A number of other factors have been analysed to determine their influence on results.

\section{SuBjECtS AND METHODS}

The 149 patients were attending either the Royal Infirmary or the Western General Hospital, Edinburgh. Their distribution according to age, sex, aetiology of heart disease, and type of arrhythmia is shown in Table I. Those with rheumatic heart disease and atrial fibrillation have been further analysed by comparing the distribution of cases according to age, sex, duration of preceding arrhythmia, valve lesion, heart size, and height of the ' $\mathrm{f}$ ' waves in one group receiving quinidine and another on

\footnotetext{
Received May 25, 1967.

* This paper was presented as a demonstration at the meetings of the British Cardiac Society and Association of Physicians of Great Britain and Ireland in Belfast, May 18 and $19,1967$.
}

no quinidine (Table II). No statistically significant difference is present between these groups.

The technique of cardioversion was similar to that described by Lown (1964). General anaesthesia was given in all cases.

Patients were admitted to hospital after digoxin and diuretics had been discontinued for two or three days. Patients in the Royal Infirmary were premedicated for 24 hours with quinidine $1 \mathrm{~g}$. in divided doses and maintained on the same daily dose following successful cardioversion. Those in the Western General Hospital were not given quinidine before or after the procedure. Although not included in our analysis, 12 per cent of patients premedicated with quinidine converted to sinus rhythm without electrical shock. Anticoagulants were started at least three weeks before conversion in 35 patients with a history of embolic phenomena and 18 in whom clot had been demonstrated in the left atrium at operation or where atrial fibrillation was of recent onset. Five patients with prosthetic valves were already on anticoagulants.

Those patients who were successfully converted were reviewed as out-patients within the first month and thereafter every three months so long as sinus rhythm persisted. Over 80 per cent of patients have been followed for more than three months and 40 per cent for over a year. Three patients were lost to follow-up after less than a month. At each visit serum quinidine levels were estimated (Brodie et al., 1947). These levels varied between patients and in the same patient on different occasions, but the mean level throughout the study was $2 \cdot 2 \mathrm{mg}$. per 1 . $(S D \pm 1 \cdot 1)$. Quinidine was stopped when reversion to an arrhythmia occurred.

\section{RESULTS}

The results in the 94 patients with rheumatic heart disease and atrial fibrillation detailed in Table II are shown in Fig. 1. Maintenance of sinus rhythm following conversion is not significantly influenced by omission or use of quinidine in the dose selected for this study (Fig. 2a and b). In both sub84 
TABLE I

DISTRIBUTION OF CASES ACCORDING TO AGE, SEX, ARRHYTHMIA, AND AETIOLOGY OF HEART DISEASE

\begin{tabular}{|c|c|c|c|c|c|c|c|c|c|c|}
\hline \multirow{3}{*}{$\begin{array}{c}\text { Heart } \\
\text { disease }\end{array}$} & \multirow{3}{*}{$\begin{array}{c}\text { No. } \\
\text { of } \\
\text { patients }\end{array}$} & \multirow{3}{*}{$\begin{array}{l}\text { Atrial } \\
\text { fibril- } \\
\text { lation }\end{array}$} & \multirow{3}{*}{$\begin{array}{l}\text { Atrial } \\
\text { flutter }\end{array}$} & \multirow{3}{*}{$\begin{array}{c}\text { Paroxy- } \\
\text { smal } \\
\text { atrial } \\
\text { tachy- } \\
\text { cardia } \\
\text { (not } \\
\text { digitalis } \\
\text { induced) }\end{array}$} & \multicolumn{3}{|c|}{ Men } & \multicolumn{3}{|c|}{ Women } \\
\hline & & & & & \multirow{2}{*}{ No. } & \multicolumn{2}{|c|}{ Age (yr.) } & \multirow{2}{*}{ No. } & \multicolumn{2}{|c|}{ Age (yr.) } \\
\hline & & & & & & Range & Mean & & Range & Mean \\
\hline Rheumatic & 97 & 94 & 2 & 1 & 32 & $19-65$ & 46 & 65 & $19-58$ & 44 \\
\hline Non-rheumatic & 52 & 35 & 11 & 6 & 40 & $26-73$ & 52 & 12 & $21-70$ & 42 \\
\hline $\begin{array}{l}\text { Ischaemic } \\
\text { Hypertensive } \\
\text { 'Lone' } \\
\text { Thyrotoxic† } \\
\text { Congenital } \neq \\
\text { Myopathic } \\
\text { Miscellaneous }\end{array}$ & $\begin{array}{r}11 \\
5 \\
13 \\
5 \\
9 \\
5 \\
4\end{array}$ & $\begin{array}{r}5 \\
5 \\
5 \\
11 \\
4 \\
3 \\
5 \\
2\end{array}$ & $\begin{array}{l}2 \\
0 \\
1 \\
1 \\
5 \\
0 \\
2\end{array}$ & $\begin{array}{l}4 \\
0 \\
1 \\
0 \\
1 \\
1 \\
0 \\
0\end{array}$ & $\begin{array}{r}11 \\
4 \\
12 \\
4 \\
2 \\
4 \\
3\end{array}$ & $\begin{array}{l}50-73 \\
43-64 \\
35-70 \\
54-64 \\
26-52 \\
26-46 \\
47-66\end{array}$ & $\begin{array}{l}66 \\
54 \\
49 \\
59 \\
39 \\
37 \\
57\end{array}$ & $\begin{array}{l}-1 \\
1 \\
1 \\
7 \\
1 \\
1\end{array}$ & $\begin{array}{c}70 \\
46 \\
46 \\
21-56 \\
50 \\
16\end{array}$ & $\begin{array}{l}70 \\
46 \\
46 \\
40 \\
50 \\
16\end{array}$ \\
\hline
\end{tabular}

* 5 had electrocardiographic evidence of previous myocardial infarction.

† One patient had undetected thyrotoxicosis at the time of conversion.

$¥$ All had post-operative atrial septal defect; 5 ostium primum; 7 ostium secundum.

followed for over a year maintained sinus rhythm. Results are expressed as percentages of the number of patients successfully converted and followed for specific time periods. One patient with atrial flutter failed to convert, while the other, along with the patient with paroxysmal atrial tachycardia, maintained sinus rhythm for over three months.

In the non-rheumatic group there were 52 patients of whom 32 were premedicated with quinidine, but the value of this drug was not assessed because of the

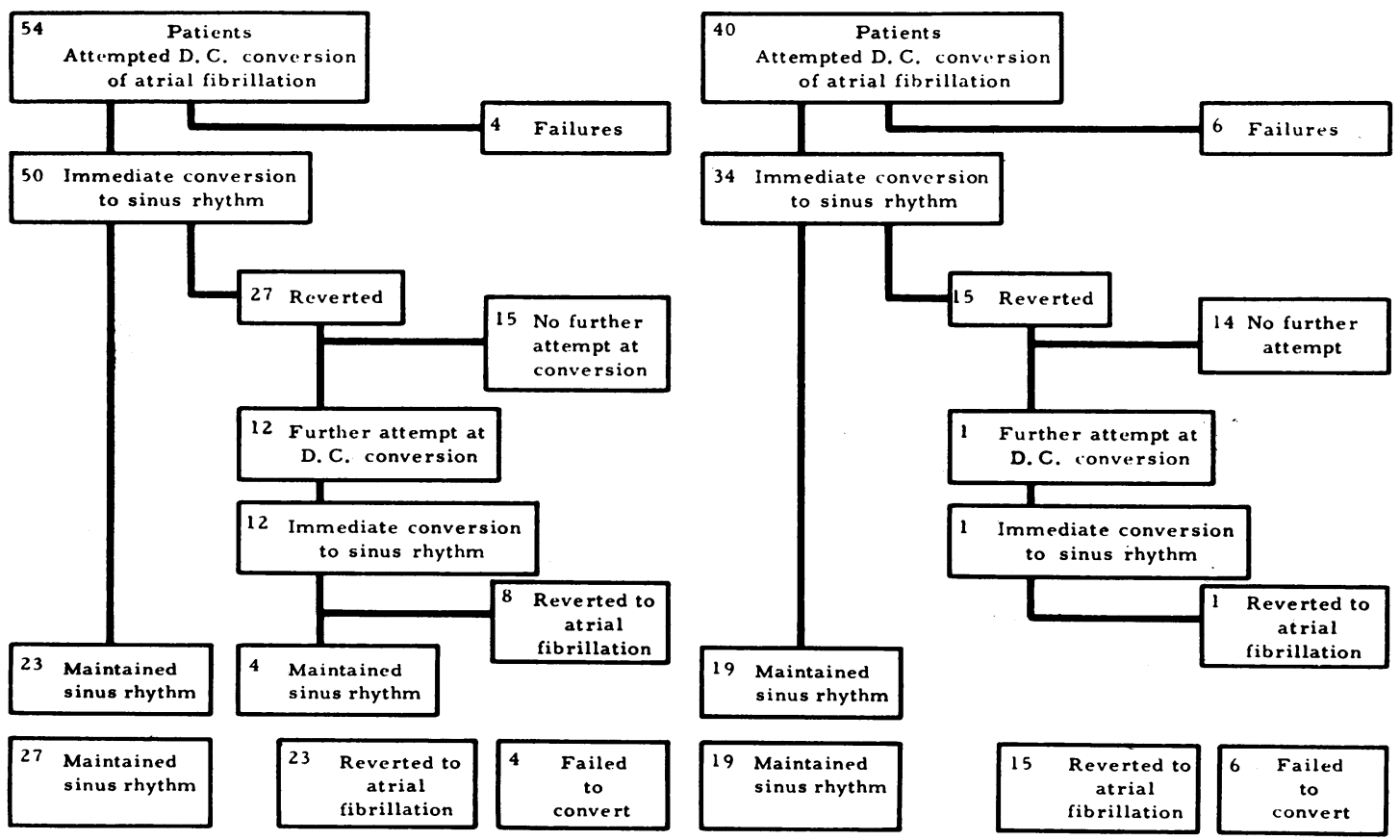

FIG. 1.-Rheumatic heart disease. The outcome of treating atrial fibrillation with DC shock in a group of patients on prophylactic quinidine and a comparable group not on quinidine. 
TABLE II

RHEUMATIC HEART DISEASE, ATRIAL FIBRILLATION: DISTRIBUTION OF PATIENTS ACCORDING TO CERTAIN FACTORS IN THOSE RECEIVING QUINIDINE AND THOSE ON NO QUINIDINE

\begin{tabular}{|c|c|c|c|}
\hline & & $\begin{array}{l}\text { No } \\
\text { quinidine }\end{array}$ & Quinidine \\
\hline Age (yr.) & $\left\{\begin{array}{l}<50 \\
50 \text { and over }\end{array}\right.$ & $\begin{array}{l}29 \\
11\end{array}$ & $\begin{array}{l}41 \\
13\end{array}$ \\
\hline Sex & Men & 11 & 22 \\
\hline Atrial fibril- & 2 or less & $\begin{array}{l}29 \\
28\end{array}$ & $\begin{array}{l}32 \\
46\end{array}$ \\
\hline $\begin{array}{l}\text { lation duration } \\
\text { (yr.) }\end{array}$ & \} Mitral stenosis: & 12 & 8 \\
\hline Valve lesion & $\left\{\begin{array}{l}\text { post-mitral } \\
\text { valvotomy } \\
\text { Mitral stenosis and }\end{array}\right.$ & 13 & 14 \\
\hline $\begin{array}{l}\text { Cardiothoracic } \\
\text { ratio ( } \%) \\
\text { Tallest 'f' wave } \\
\text { in V1 (mm.) }\end{array}$ & $\begin{array}{l}\text { incompetence } \\
\text { Mitral imcompetence } \\
\text { Multivavular lesions } \\
55 \text { or less } \\
>55 \\
2 \text { or less } \\
>2\end{array}$ & $\begin{array}{r}8 \\
3 \\
16 \\
13 \\
27 \\
27 \\
11\end{array}$ & $\begin{array}{r}10 \\
0 \\
30 \\
28 \\
26 \\
43 \\
13\end{array}$ \\
\hline
\end{tabular}

No significant difference between the groups by $\chi^{2}$.

diversity of the underlying heart disease. After successful conversion of atrial fibrillation 70 per cent of patients followed for over a year maintained sinus rhythm (Fig. 2c).

Reversion to atrial fibrillation occurred most frequently during the first three months in both rheumatic and non-rheumatic patients; subsequently the chances of reverting were substan- tially reduced (Fig. 2). Thirteen cases of rheumatic heart disease were subjected to DC shock on two occasions; all were successfully converted but 9 subsequently reverted. When reversion occurred within a month of DC shock it was seldom maintained for a longer period after a second conversion.

Other factors have been analysed in the 129 patients with atrial fibrillation to determine their influence on the initial or subsequent outcome of electrical conversion. Sex and age over or under 50 years did not significantly influence results. Only 6 per cent of patients failed to convert when the preceding arrhythmia had been present for less than two years compared with 36 per cent when the arrhythmia had been present for more than two years. Long duration of preceding arrhythmia was a less significant factor in the maintenance of sinus rhythm. Fibrillatory waves of over $2 \mathrm{~mm}$. in lead V1 favoured conversion but did not influence maintenance of sinus rhythm. Over-all cardiac size, i.e. cardiothoracic ratio, did not influence either the success of conversion or the maintenance of sinus rhythm, but in the rheumatic group all the failures had a cardiothoracic ratio of more than 55 per cent.

Most of the rheumatic patients had multivalvular defects, and this increased the chances both of failure to restore sinus rhythm and of relapse to atrial fibrillation (Table III). On the other hand, only one
NO QUINIDINE

(a)

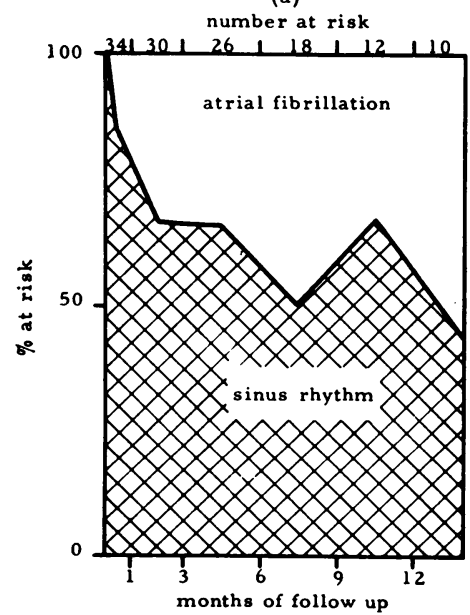

QUINIDINE

(b)

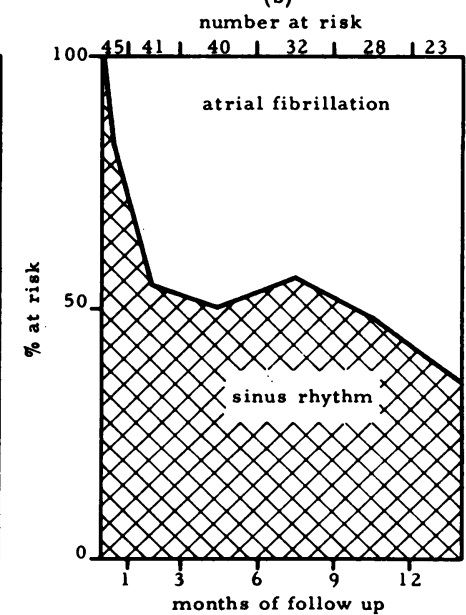

(c)

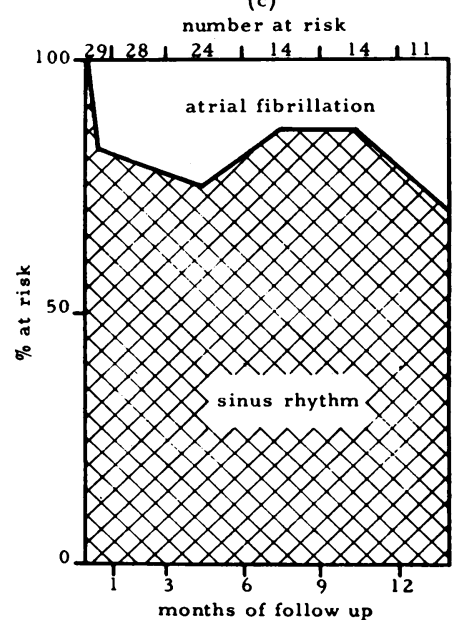

FIG. 2-Observed maintenance of sinus rhythm following DC shock in patients with atrial fibrillation. Number at risk is the number of patients successfully treated and followed for specific time intervals. Quinidine dosage was $1 \mathrm{~g}$./day. (a) and (b) rheumatic heart disease groups; (c) non-rheumatic heart disease. 
TABLE III

VALVE LESION IN PATIENTS WITH RHEUMATIC HEART DISEASE AND ATRIAL FIBRILLATION: OUTCOME OF DC SHOCK

\begin{tabular}{l|c|c|c}
\hline \multicolumn{1}{c|}{ Valve lesion } & $\begin{array}{c}\text { Main- } \\
\text { tained } \\
\text { sinus } \\
\text { rhythm }\end{array}$ & $\begin{array}{c}\text { Reverted } \\
\text { to atrial } \\
\text { fibril- } \\
\text { lation }\end{array}$ & $\begin{array}{c}\text { Failed } \\
\text { to } \\
\text { convert }\end{array}$ \\
\hline $\begin{array}{l}\text { Mitral stenosis } \\
\text { Post-mitral } \\
\text { valvotomy }\end{array}$ & 16 & 10 & 1 \\
$\begin{array}{l}\text { Mitral stenosis } \\
\text { and incompetence }\end{array}$ & 11 & 5 & 2 \\
$\begin{array}{l}\text { Mitral incompetence } \\
\text { Multivalvular defects }\end{array}$ & 17 & 1 & 0 \\
\hline
\end{tabular}

of 27 patients with mitral stenosis failed to convert after mitral valvotomy, but 10 subsequently reverted and therefore the long-term results did not differ greatly from those of other valve lesions. Mitral incompetence was associated with stenosis in 18 patients. Two patients failed to convert and 5 out of the remaining 16 reverted after variable periods. Three patients had dominant mitral incompetence; all were successfully converted and one subsequently reverted.

Sinus rhythm was restored in 60 per cent of patients with a discharge of 100 watt seconds, 35 per cent required 200 watt seconds, and the remaining 5 per cent converted with 300 watt seconds. The $\mathrm{P}-\mathrm{R}$ interval immediately after conversion was less than $0.2 \mathrm{sec}$. in 85 per cent of patients but of those with a longer $\mathrm{P}-\mathrm{R}$ interval a significant number had been premedicated with quinidine.

Transitory post-conversion arrhythmias were more common in the rheumatic group; none was serious. Supraventricular extrasystoles occurred in 47 per cent of all patients. Nodal and ventricular extrasystoles were less frequently seen in patients premedicated with quinidine. Coupled ventricular extrasystoles appeared infrequently, while atrial tachycardia, atrial fibrillation, atrial flutter, A-V block, and wandering pacemaker were rare. Of the patients premedicated with quinidine, 43 per cent

TABLE IV

TRANSITORY ARRHYTHMIAS AFTER SUCCESSFUL DC SHOCK: COMPARISON BETWEEN PATIENTS ON QUINIDINE AND THOSE WITHOUT

\begin{tabular}{c|c|c}
\hline & Quinidine & No quinidine \\
\hline Arrhythmia present & 40 & 37 \\
Arrhythmia absent & 30 & 6 \\
\hline
\end{tabular}

$\chi^{2} 0.001>\mathrm{p}$ were defibrillated without subsequent transitory arrhythmias compared with 14 per cent on no quinidine. The difference was statistically significant (Table IV). Right bundle-branch block was present in 7 of the 10 patients with congenital heart disease, but this did not influence either the immediate or the subsequent outcome of cardioversion. $\mathrm{A}-\mathrm{V}$ block was not precipitated in any of these cases.

A previously successful conversion with quinidine had been achieved in 12 patients with subsequent relapse. Direct current shock successfully converted all but one. Another 16 had failed to respond to quinidine alone ; 4 of these were also resistant to electrical conversion.

The majority of patients on quinidine tolerated it well, but 9 of 86 patients had side effects. Diarrhoea and nausea were the most frequent complaints, while blurred vision, tinnitus, headache, and dullness of hearing were less common. The only more serious complication was one case of transient thrombocytopenia. Electrocardiographic signs of quinidine toxicity were not encountered.

There were no deaths and only one embolic episode. A transient hemiparesis developed 18 hours after cardioversion in a patient who had not received anticoagulants before the procedure.

\section{Discussion}

Successful conversion of supraventricular arrhythmias to sinus rhythm in rheumatic and nonrheumatic groups was achieved in 88 per cent of the patients. This corresponds with the experience of others (Lown et al., 1963; Lown, Kleiger, and Wolff, 1964 ; Oram and Davies, 1964 ; Korsgren et al., 1965; Halmos, 1966; Szekely et al., 1966; Morris et al., 1966). On the other hand, Holzman and Brown (1951), reviewing earlier experience with quinidine conversion, quoted an initial mean success rate of 67 per cent. More recently, Goldman (1960) achieved initial success with quinidine in 82 per cent of cases, but added that results were dependent on the underlying heart disease.

Long-term results of cardioversion are frequently reported as percentages of the total number of successfully treated cases who maintain sinus rhythm. This method does not indicate the duration of maintained sinus rhythm and for this reason our results are expressed as percentages of the number of patients successfully treated and followed for specific time intervals. In contrast to the method of Morris et al. (1966) this does not include results from cardioversions carried out on two occasions and therefore represents the observed maintenance of sinus rhythm following a single cardioversion. 
Although the electrical method of restoring sinus rhythm has considerable advantages, it does not influence the maintenance of sinus rhythm once established. Many authors state that without the prophylactic use of quinidine the majority of patients inevitably revert to atrial fibrillation within a short time (Goldman, 1960 ; Sokolow and Perloff, 1961 ; Hurst et al., 1964 ; Lown, 1964).

In the present study patients with rheumatic heart disease were divided into two comparable groups. The first was premedicated with quinidine and this drug was continued after successful direct current conversion while the second group did not have quinidine. There was no significant difference in the number of cases maintaining sinus rhythm in either group. The dose of quinidine $(1 \mathrm{~g}$./day in divided doses) was similar to that used by Reinikainen et al. (1965) and Szekely et al. (1966), and the mean serum level was the same as that reported by Rossi and Lown (1967). Our follow-up results are comparable to those of Korsgren et al. (1965) who gave 2 g. quinidine per day. Differences in presentation of results make comparison between series difficult, because in many studies results are grouped according to the arrhythmia without special emphasis on aetiology, while in others follow-up periods have been short.

The number of non-rheumatic cases which maintained normal sinus rhythm for over a year was significantly greater than in the rheumatic group. Morris et al. (1966) showed that patients with ischaemic and hypertensive heart disease had a high recurrence rate of atrial fibrillation but in small numbers we have not confirmed this.

Over a third of those cases which reverted to their original arrhythmia did so within three months of conversion, and similar experience has been reported by Korsgren et al. (1965), Hurst et al. (1964), and Morris et al. (1964, 1966). The suggestion that premedication with quinidine avoids early recurrence of atrial fibrillation in the immediate postconversion period (Morris et al., 1964 ; Reinikainen et al., 1965; Rossi and Lown, 1967) has not been confirmed by this study.

There is, in general, little advantage in reconverting patients who revert within a month of cardioversion (Morris et al., 1964; Korsgren et al., 1965). Although it is not possible to predict the outcome in any individual case, it is suggested that reconversion should be attempted if the precipitating cause for reversion to an arrhythmia has been transitory, such as operation, severe emotional stress, or an intercurrent infection.

It is clear that DC shock is not always successful and only a proportion of those converted can be expected to maintain sinus rhythm for sufficient time to justify the procedure. In patients with atrial fibrillation a number of other factors were studied to determine their influence on results.

A preceding arrhythmia of longer than two years' duration was an adverse factor in determining the success of initial conversion and the frequency of subsequent reversion. Similar observations were noted in attempted conversion with quinidine (Goldman, 1960 ; Rokseth and Storstein, 1963) and more recently with electrical conversion (Korsgren et al., 1965). Oram and Davies (1964) and Halmos (1966) showed that in atrial fibrillation from all causes the chances of failing to convert the arrhythmia were greater when the fibrillatory waves were small. In our series similar results were obtained, particularly in the non-rheumatic group, but reversion to atrial fibrillation was not influenced by the amplitude of the initial ' $f$ ' waves. The cardiothoracic ratio did not affect either the success or the maintenance of sinus rhythm in the non-rheumatic heart disease group, possibly because the precipitating cause of the cardiomegaly, such as atrial septal defect or hypertension, had been treated. On the other hand, all the failures in the rheumatic heart disease group had cardiothoracic ratios of greater than 55 per cent, but like Oram and Davies (1964) and Halmos (1966) we were more impressed by the number of such patients who were successfully converted $(75 \%)$. Duration of maintained sinus rhythm in the rheumatic group was not significantly affected by cardiomegaly. As previously shown with quinidine (Logan and Turner, 1953), patients with isolated mitral stenosis complicated by atrial fibrillation and treated by valvotomy responded well to direct current shock; only one patient failed to convert to sinus rhythm. But even in this favourable group reversion to atrial fibrillation did not differ from those patients with other valvular defects. In the latter group there was a higher rate of initial failure.

We were unable to confirm the observations of Lown et al. (1963) that the P-R interval tended to be prolonged after cardioversion. In our series 85 per cent had $P-R$ intervals of less than $0.2 \mathrm{sec}$. immediately after conversion. Of the 17 patients who did have a $P-R$ interval of over $0.2 \mathrm{sec}$., 15 had been premedicated with quinidine. Prolongation of the P-R interval is known to be an action of quinidine (Holzman and Brown, 1951; Sokolow and Perloff, 1961). It has also been shown that following electrical conversion, latent features of digitalis toxicity such as first degree heart block may become manifest (Gilbert and Cuddy, 1964).

After successful conversion there is a potential risk of precipitating acute congestive cardiac failure if uncontrolled atrial fibrillation returns. The risk 
is increased in cases on maintenance quinidine, particularly when digitalis has been discontinued after restoration of sinus rhythm. This point was emphasized by Oram and Davies (1964). Most of our patients did receive digitalis as well as quinidine following conversion but some were not on digitalis. One patient had to be readmitted for treatment of congestive cardiac failure on reversion to atrial fibrillation.

Transitory post-conversion arrhythmias were common but not serious. Premedication with quinidine significantly reduced their frequency, an observation noted previously by Lemberg et al. (1964) and Rossi and Lown (1967).

\section{SUMMARY}

Direct current shock was used to treat 149 patients with atrial arrhythmias. Sinus rhythm was established in 88 per cent. Rheumatic patients with atrial fibrillation were divided into two comparable groups. The first received quinidine (1 g. per day) 24 hours before the procedure, and following successful cardioversion patients were maintained on the same daily dose. The mean serum quinidine level was $2 \cdot 2 \mathrm{mg} . / 1$. ( $S D \pm 1 \cdot 1)$. Quinidine was not given to the second group. Observed maintenance of sinus rhythm following DC shock was not statistically different in the two groups. In patients followed for over a year about 45 per cent maintained sinus rhythm, which contrasted with the nonrheumatic group where 70 per cent maintained sinus rhythm over the same period. There was little advantage in reconverting cases who reverted within a month of cardioversion.

When the preceding arrhythmia had been present for more than two years the chances of initial successful conversion and subsequent maintenance of sinus rhythm were reduced. Small ' $f$ ' waves also increased the chances of initial failure but did not influence the maintenance of sinus rhythm. Heart size did not affect results, but in the rheumatic group all the failures had a cardiothoracic ratio greater than 55 per cent. Although patients with isolated mitral stenosis complicated by atrial fibrillation and treated by valvotomy responded well to DC shock, reversion to atrial fibrillation was as frequent as in those patients with other valvular defects. In the latter group the initial failure rate was higher.

Transitory post-conversion arrhythmias were common but not serious. Premedication with quinidine significantly reduced their frequency. Ten per cent of patients on quinidine had side effects, mainly gastro-intestinal; one patient developed transient thrombocytopenia.
In patients with rheumatic heart disease it is concluded that, following cardioversion, prophylactic quinidine, achieving a mean serum level of $2.2 \mathrm{mg}$./1., does not increase the chances of maintaining sinus rhythm.

We would like to thank Dr. R. M. Marquis, Dr. R. W. D. Turner, Dr. M. F. Oliver, Dr. M. B. Matthews, Dr. D. G. Julian, and Dr. A. H. Kitchin for allowing us to treat patients under their care and for their helpful advice on the preparation of the manuscript. We are indebted to the British Heart Foundation for providing the Lown Cardioverters used in this study and to Dr. L. Tompsett who estimated the serum quinidine levels.

\section{REFERENCES}

Brodie, B. B., Udenfriend, S., Dill, W., and Downing, G. (1947). The estimation of basic organic compounds in biological material. $\mathcal{f}$. biol. Chem., 168, 311 .

Davies, P., Leak, D., and Oram, S. (1965). Quinidineinduced syncope. Brit. med. F., 2, 517.

Gilbert, R., and Cuddy, R. P. (1964). Digitalis intoxication following conversion to sinus rhythm (abstract). Circulation, 30, Suppl. 111, 83.

Goldman, M. J. (1960). The management of chronic atrial fibrillation : indications for and method of conversion to sinus rhythm. Progr. cardiovasc. Dis., 2, 465.

Halmos, P. B. (1966). Direct current conversion of atrial fibrillation. Brit. Heart F., 28, 302.

Holzman, D., and Brown, M. G. (1951). The use of quinidine in established auricular fibrillation and flutter. Amer. F. med. Sci., 222, 644.

Hurst, J. W., Paulk, E. A., Proctor, H. D., and Schlant, R. C. (1964). Management of patients with atrial fibrillation. Amer. F. Med., 37, 728.

Korsgren, M., Leskinen, E., Peterhoff, V., Bradley, E., and Varnauskas, E. (1965). Conversion of atrial arrhythmias with DC Shock. Acta med. scand., Suppl. 431.

Lemberg, L., Castellanos, A., Swenson, J., and Gosselin, A. (1964). Arrhythmias related to cardioversion. Circulation, 30, 163.

Logan, A., and Turner, R. (1953). Mitral stenosis, diagnosis and treatment. Lancet, 1, 1007 and 1057.

Lown, B. (1964). "Cardioversion" of arrhythmias (i) and (ii). Mod. Conc. cardiovasc. Dis., 33, 863 and 869.

—, Amarasingham, R., and Neuman, J. (1962). New method for terminating cardiac arrhythmias: use of synchronized capacitor discharge. $\mathcal{F}$. Amer. med. Ass., $182,548$.

- Kleiger, R., and Wolff, G. (1964). The technique of cardioversion. Amer. Heart f., 67, 282.

—, Perlroth, M. G., Kaidbey, S., Abe, T., and Harken, D. E. (1963). "Cardioversion" of atrial fibrillation. A report on the treatment of 65 episodes in 50 patients. New Engl. f. Med., 269, 325.

Morris, J. J., Kong, Y., North, W. C., and McIntosh, H. D. (1964). Experience with "cardioversion" of atrial fibrillation and flutter. Amer. F. Cardiol., 14, 94.

—, Peter, R. H., and McIntosh, H. D. (1966). Electrical conversion of atrial fibrillation. Ann. intern. Med., 65, 216.

Oram, S., and Davies, J. P. H. (1964). Further experience of electrical conversion of atrial fibrillation to sinus rhythm: analysis of 100 patients. Lancet, 1, 1294.

-Reinikainen, M., Koskinen, P., Pöntinen, P., and Siitonen, L. 
(1965). Experiences in the use of direct current countershock in the treatment of cardiac arrhythmias. Acta med. scand., Suppl. 437.

Rokseth, R., and Storstein, O. (1963). Quinidine therapy of chronic auricular fibrillation. Arch. intern. Med., 111, 184.

Rossi, M., and Lown, B. (1967). The use of quinidine in cardioversion. Amer. F. Cardiol., 19, 234.
Sokolow, M., and Perloff, D. B. (1961). The clinical pharmacology and use of quinidine in heart disease. Progr. cardiovasc. Dis., 3, 316.

Szekely, P., Batson, G. A., and Stark, D. C. C. (1966). Direct current shock therapy of cardiac arrhythmias. Brit. Heart F., 28, 366.

Thomson, G. W. (1956). Quinidine as a cause of sudden death. Circulation, 14, 757. 